\title{
Parenting Mixed Children: How to Start the Conversation About Identity
}

\author{
Laura Bures
}

\begin{abstract}
This paper explores the parenting practices of mixed union couples in Canada in an attempt to understand how these practices influence identity development in biracial children. Current theories around this topic suggest that the type of parental communication a biracial child receives influences their decision to associate with both racial identities, one racial identity, or neither. I will discuss common sources of tension that these couples face in their negotiation of racial and cultural differences. I suggest that when interracial couples disagree on how to parent their children about their mixed identities, children struggle to develop a strong understanding of who they are.
\end{abstract}

Laura Bures is an undergraduate student in Sociology at MacEwan University. Laura works part time at various elementary schools in Edmonton with children who have recently immigrated to Canada. She wishes to complete her Bachelor of Sociology degree and pursue a career involved in children's services. 
Bures

\section{Introduction}

In 2011, Statistics Canada released a report titled "Mixed Unions in Canada," based on the National Household Survey. The survey, which is currently still the most recent data available on this topic, defined mixed unions as couples where one partner identifies with a visible minority group, and the other does not, or where both partners belong to different minority groups. Minority groups include, but are not limited to: South Asian, Chinese, Black, Filipino, Latin American, Arab, Southeast Asian, West Asian, Korean and Japanese (Statistics Canada, 2011, p. 3). As of this 2011 data, Canada has approximately 360,045 mixed unions, which is just under 5 percent. In line with past censuses conducted in 1991 and 2006, couples in mixed union relationships, whether marriage or common law, have been on the rise in Canada. In fact, the rate of intermarriage increased from $2.6 \%$ of all unions in 1991 to $3.1 \%$ in 2001 and 3.9\% in 2006 (Statistics Canada, 2008). The "Mixed Unions in Canada" report also reveals that these relationships are becoming increasingly common across younger generations, suggesting this trend is here to stay.

Although there are no official numbers related to how many of these couples go on to have children, data would suggest that these numbers would also be high as Canada has continued to see an influx in immigration (Hamplova \& Le Bourdais, 2010). Researchers have begun to pay particular attention to the parenting practices of interracial couples and the implications of these practices on multiracial children. This paper will examine how interracial couples negotiate and explain "race" to their children, along with various challenges related to parenting from two different backgrounds. I will examine how parents' decisions on whether or not to talk to their children about race within the home can impact a child's identity development. I hypothesize that interracial children look toward their parents and interactions within the family to form a cultural identity and proper understanding of race. When there is conflict among interracial couples on how to educate their children about race, children struggle to understand who they are.

\section{Views on Interracial Unions in Canada}

Before jumping into how interracial couples educate their children about race, it is important to examine views on interracial relationships in Canada. The reoccurring claim that Canada is a multicultural country is often used socially and politically to reduce racial and cultural inequalities while still maintaining cultural diversity (Lalonde, Giguere, Fontaine \& Smith, 2007). In fact, multiculturalism is viewed as a positive and integral part of Canadian identity (Lalonde, 2002). Although researchers often argue this claim, it is important to recognize that Canada was the first country ever to adopt a policy of multiculturalism with the goal to harmonize race relationships (Hamplova and Le Bourdais, 2010). This is important when examining interracial unions because "levels of interracial or intercultural marriage are commonly used to measure "the openness of societies and the degree of equality among people of various ethnic, racial, or cultural origins" (Hamplova and Le Bourdais, 2010, p. 1537). Research has shown that metropolitan cities like Vancouver and Toronto report the highest levels of interracial unions, and that these numbers will continue to increase as Canada continues to accept immigrant populations (Hamplova and Le Bourdais, 2010). This country can therefore be viewed as one that is relatively accepting of interracial unions. On the flip side, the prevalence of intermarriage within Canada does pose a 
series of challenges and changes to Canadian family structure. Interracial couples often struggle to negotiate cultural difference as part of everyday family life when parenting their children (Edwards, Cabaellero and Puthussery, 2010).

\section{Literature Review}

In social sciences, Erik Erikson is one of the most influential theorists in the study of social and moral identity acquisition from childhood to adulthood. Some of the key stages in his theory of child development include autonomy from parents, relating to peers, developing a sense of self, and self-differentiating from others (Erikson, 1968). For biracial individuals, there are often additional challenges posed within these stages due to the ambiguous nature of being raised in two distinctly different racial and cultural identities and having to negotiate between the two (Herman, 2004). As a result, there are many conflicting views and models in literature related to the social and phycological factors that impact a biracial child's choice of race identification. Jacobs' (1992) model of multiracial identity development is one of the most popularized theories in relation to this topic. His model includes three stages that affect a child's understanding of their racial identity. The first stage, defined as a precolour stage, occurs when a child experiments with understandings of colour and racial identities. The second stage, defined as racial ambivalence, is the marking point in a child's development when they have a broader understanding of colour, and the social meanings attached to colour. The final stage is called the racial identity stage, where children thoroughly understand that belonging to a racial group is associated with skin colour, but also with parentage, social norms, and personal choice (Jacobs, 1992). To summarize, this theory suggests that consciousness of race first begins with skin colour and then goes on to encompasses ancestry, norms, and self-choice, all aspects of one's identity.

Poston and Root are two key theorists responsible for the current models most commonly accounted for when studying the development of identities in biracial children (Jones, 2015). Poston's (1990) model includes five aspects of positive racial identity development: personal identity, choice of group categorization, enmeshment/denial, appreciation, and integration. In the first stage, personal identity, individuals are often very young and are uncertain about the impacts of race/ethnicity on their lives. As a result, they lack a salient membership in any ethnic group. Eventually these individuals are pushed by various pressures around them including social groups and peers to choose an identity, usually of one ethnic group. This is the group categorization stage, an ambivalent time in an individual's life. Third, during the enmeshment/denial stage, biracial individuals often experience guilt associated with having to choose a background that may not fully express their mixed identity. It is common to see individuals in this stage feel angry or ashamed of having to juggle two different ethnicities, especially when one of those identities happens to be a noticeable minority. The fourth stage occurs when one begins to appreciate their mixed heritage and takes initiative to embrace certain aspects of both identities. Even if the individual still chooses to identify with one group over the other, they are more inclined to learn about and share aspects of both identities. The last stage is the integration stage, where biracial individuals learn to recognize and cherish their mixed identities. During this stage, a salient, integrated identity is developed (Poston, 1990).

Similar to Poston's model, Root (2003) suggests that there are four outcomes of a positive 
biracial identity: acceptance of the identity assigned by society, identification with both racial groups, identification with one racial group, or identification as a new racial group. Root's model emphasizes social prejudice in society and how power struggles between dominant and subordinate racial groups affect biracial individual's decisions on how to self-identify (Root, 2003).

In regard to interracial parenting, literature seems to focus on the different approaches interracial couples take to educate their children about race. Much of this literature discusses how parents explain their cultural differences to their children and how race is talked about within the household (Craword \& Alaggia, 2008). To make things more complicated, there is increasing debate on how interracial parents should parent their children and educate them about race. Although Canada may seem accepting of cultural difference, a persistent societal myth exists for interracial parents in that "society will define your child as coloured, so you should raise them as coloured" (Melina, 1990, p. 2). Researchers like Root (2005) claim that family environment is critical within mixed households in helping the child understand their heritage and value both races. Parents serve as the primary educators on race and can heavily influence how their children choose to identify. How comfortable their children are with that identity is dependent on number of factors related to parenting and family experiences within the home (Ingram \& Chaudhary, 2014). Similarly, Brooks (2007) proposes that the type of parental communication a biracial child receives within the home is a strong predictor of whether they choose to adopt a mono-racial, mixed, or transcendent identity.

Edwards, Cabaellero, \& Puthussery (2009) conducted a qualitative study of how interracial couples understand and negotiate cultural difference when teaching race to their children. Three common parenting styles were identified in this study: open individualized, mix collective and single collective. An open individualized parenting style is when parents encourage their children to focus on their own potential and abilities rather than have cultural expectations forced onto them. In this setting, “children's identity and sense of belonging are not seen as necessarily rooted in particular racial, ethnic, or religious backgrounds" (Edwards, Cabellero, \& Puthssery, 2009, p. 954). Parents encourage children to think beyond these categories and explore other realms of their identities. In this parenting style, couples refrain from talking about race within the household. Instead, they teach their children that their identity can come from their own choosing; they can express themselves and adopt any culture they choose. In a mix collective household, parents encourage integration and open discussion of both heritages. These parents often see racial backgrounds as an undisputable part of the child's identity. Children are taught about the different parts of their heritage and encouraged to acknowledge and participate in the practices and understandings of both parent's racial and ethnic identities. Parents openly talk about race with their children along with the societal advantages and disadvantages attributed to it. Children are often taught about racial stereotypes and negative assumptions that others may have of them. Parents use their own experiences with prejudice and/or talk about privileges related to race as a form of education. Finally, a single collective parenting style occurs when "only one aspect of children's background is stressed, and a sense of belonging is promoted for them through that" (Edwards, Cabellero, \& Puthssery, 2009, p. 957). In these households, only a single racial/ethnic classification and its cultural practices are welcomed. Children are encouraged to take on an identity similar to that of only one of their parents. Race is still talked about in the household, but talk and understanding of one race is promoted over the other. 
So, what happens when there is conflict among interracial couples on how to talk to their child about race, and how might this impact the child's ability to grasp a true understanding of who they are? In Canada, which is considered to be an accepting and multicultural society, should these parents encourage their children to embrace both ethnicities within the home? I propose that interracial parents should provide cultural experiences within the home and openly talk about race so that their child will have a better understanding of who they are. A mix collective household (Edwards, Cabellero, \& Puthssery, 2009) is therefore the best parenting approach for interracial couples in Canada, a country that prides itself in being multicultural. Unlike the United States, whose Melting Pot theory expects minority cultures to practice the norms, values and behaviors that reflect the dominant culture, Canada is thought to be more accepting of diversity (Berry, 2019). With this perspective, interracial couples should incorporate the practices and teachings of both heritages within the home so that their children grow up confident and certain about both aspects of their mixed identity.

\section{Parental Socialization About Race}

In a study of interracial households, Craword \& Alaggia (2008) examine what family practices play a significant role in helping biracial children develop a positive racial identity. Three themes emerged: (1) level of parental awareness and understanding of race issues; (2); impact of family structure; and (3) willingness and communication to talk about race issues. Prior to this study, research suggested that interracial couples struggle to find appropriate ways to talk about race with their mixed-race children. For example, Root (2005) found that silence often came up in regard to the topic of race with these families because of the pain it evokes. Similarly, O'Donoghue (2004) revealed in a qualitative study of 11 interracial parents that raising children forced these couples to recognize and confront many realities that they had the privilege of never having to previously contemplate. In Craword and Alaggia's (2008) study, which conducted of interviews from a large urban centre in central Canada, the researchers asked a group of biracial individuals the following questions: How did your parents teach you about race and racism? How do you define yourself in terms of race? How do you react when people ask you about your cultural background? (p. 86).

The biracial participants in this study identified that forming a racial identity was influenced most by their family's degree of openness to discuss race issues, and how well they were able to communicate with them during these conversations. Close to half of the individuals in this study revealed that their parents had a difficult time bringing up the topic of race at home and as a result it was often a topic 'swept under the carpet.' In households where parents were unable to openly communicate with their child on issues concerning race, or where they could not agree on how to have a conversation about it, biracial individuals reported feeling alone with "unanswered questions and difficult experiences left unacknowledged (Craword \& Alaggia, 2008, p. 91). They also revealed that the failure of their parents to discuss race inside their home acted as a disadvantage once they experienced racism growing up. This lack of communication left these children unprepared and vulnerable. The individuals whose parents frequently talked with them about race stated that they felt confident in their ability to handle difficult situations and racial encounters growing up. They also revealed that these conversations helped them "face the world with certainty" and have a stable understanding of who they are (Craword \& Alaggia, 2008, p. 92). 
It is clear from this study that when parents disagree on how to talk to their children about race, or fail to discuss the topic at all, children lack a sense of certainty in regard to their identity. As a result, they are often left confused and unsure about how to handle difficult situations. The findings also support the idea that children look up to their parents when they have issues concerning race. Parents who are adequately prepared to have these conversations may be able to help their child develop a clearer sense of who they are. In contrast, children who are raised in households where their parents fail to have open conversations about race are placed at a higher risk of being uncertain of their identity.

\section{Common Sources of Tension}

When looking at the available research on interracial parenting, a strong emphasis is often placed on the efforts interracial parents take to socialize their children about race including what it means to be a coloured person in society. Rockquemore and Laszloffy (2005) identify this as a source of tension for couples because it often requires them to negotiate racial differences. This socialization can be especially hard for white parents because prior to having a biracial child, there is a good chance that these individuals may have been oblivious to the presence of racism in North America. This reality is important to coloured minority parents because they often rely on their white partner for support in socializing their child about discrimination and the importance of their culture's history and heritage (Lamb, 1999). This form of racial socialization is extremely important for parents to initiate because it can help their child understand where they came from. It can also help them come to terms with why others may judge or perceive them in a particular way (Rockquemore \& Laszloffy, 2005).

In another Canadian study, Kourtizin (2016) examines the role that white birth mothers of non-white children play in helping their child adopt aspects of their father's heritage including language, cultures, and worldviews. This study was conducted to better understand how these women, a part of the dominant culture in Canadian society, help their child identify with their 'Other' racial, cultural and linguistic background. Kourtizin chose to examine white mothers, whom do not share their children or partners experiences of racialization and discrimination, to understand how they support their child develop a sense of who they are. The fathers in this study were all Hispanic and born outside of Canada. It is important to note that Kourtizin herself is a white mother who is married to and has biracial children with a Japanese man. Her research question, one that is relevant to her own lived experience, is 'How do White mothers prepare their mixed parentage children to live within (and against) the dominant Canadian culture?' (Kourtizin, 2016, p. 739).

Multiple interviews were conducted on the mothers in Vancouver, B.C. One mother, under the pseudo name Sarah, talks about how she encourages her mixed Columbian children to appreciate their father's heritage. Sarah felt a personal responsibility as a white mother to ensure her family makes frequent trips to Columbia. She also encourages her husband to invite his relatives into their home whenever possible. Sarah hopes that by keeping her household a Spanishspeaking one, her children will grow up listening to and learning her father's native language. She states, "cultural diversity is a given. In Canada, it's a reality. But it's good and should be celebrated" (Kourtizin, 2016, p. 742). In contrast, two of the other mothers in the study admitted 
that they did not feel it is their responsibility to help maintain the father's culture within their home. In fact, one mother stated that this aspect is "totally up to him - as painful as that is" (Kourtizin, 2016, p. 744). These comments indicate that tension can arise in interracial unions during times when there is disagreement on who is responsible for teaching children about their mixed heritage. Kourtizin believes that some of the mothers in this study "bought into the societal expectation that their husbands would take sole responsibility for teaching the minority language and culture" (2016, p. 744). When this failed to happen, the mothers reported feeling as though their children lacked a strong membership with their father's race and ethnicity. As a result, these biracial children grew up in a Canada with inadequate understandings of their mixed identities. This study suggests that when there is conflict between interracial couple on how to educate their children about their mixed races, these children struggle to understand who they are.

Kourtizin ends the study with a discussion of the common themes that resonated across all of the mother's stories. In all cases, the mothers expressed guilt and regret that their children were unable to speak the same native language as their father. They believed that speaking a different language would have been viewed positively in Canadian society, which is a multilingual country (Kourtizin, 2016, p. 744). By failing to practice aspects of the father's culture within the home, the mothers expressed feeling guilty that their children grew up in a home that did not value their fathers' language or culture (Kourtizin, 2016, p. 744). Similarly, each of the mothers admitted to feeling upset due to their inability to fully understand the experiences of their biracial children, especially when their children encountered forms of racism later on in their lives. These statements suggest that when only one race or heritage is practiced and encouraged within the home, biracial children are unable to fully identify with and appreciate both aspects of their mixed identity.

\section{Pro-active Approaches to Communicating About Race}

As identified in Craword and Alaggia's study on Canadian biracial individuals, the ability for parents to talk openly about race within the home can directly impact their child's identity development. So, what can parents do to encourage open communication around the topic of race with their children? Ingram and Chaudhary (2014) sought to figure out the answer to this question. In a qualitative study, they asked a group of biracial children to identify what they wished their parents would have done differently when having conversations with them about race. In this study, around half of the children had parents who talked openly with them about their racial identity and encouraged pride in their biracial heritage. The other half of the participants had parents who did not engage in any of these conversations. For the children who grew up in households where race was not talked about, the following comments were made: I wish my parents... Talked to me more about race; Told me how to deal with my race; Enrolled me in a more diverse school/neighborhood; Taught me to learn their language; Taught me more about my cultural heritage; Acknowledged that I am biracial; Exposed me to more diverse media (Ingram \& Chaudhary, 2014, p. 9). Similarly, most of the children in this study also reported minimal exposure to books, films, and music within their family home related to the racial heritage of one their parents. Some of these children also reported having little exposure to adult role models who shared the same racial heritage as one of their parents. These findings suggest that interracial parents may be failing to provide the necessary knowledge or resources that promote racial socialization for their children (Ingram \& Chaudhary, 2014, p. 11). 
This study offers insight in regard to how interracial parents can foster better communication with their children so that they can develop a positive racial identity. Ingram and Chaudhary conclude their study with the suggestion that parents of biracial children should consider their child's environment and review whether or not they engage in socialization practices that reflect both their heritages. The researchers also suggest that parents should provide opportunities for their children to interact with other mixed-race children and role models who display positive representations of both heritages (Ingram \& Chaudhary, 2014, p. 11).

\section{Cultural Socialization}

What other types of socialization practices can interracial couples engage in to support their child's positive identity development? As mentioned before, interracial parents sometimes struggle to agree on how to have open and appropriate conversations about race with their children. As a result, these children are often unsure about who they are and struggle to understand their own experiences of race. Rollins and Hunter (2013) conducted a study to identify other types of socialization practices interracial parents can use to support their child's identity development. These researchers pose the idea that biracial children learn to negotiate and understand their mixed memberships through different socialization messages provided by their parents. An example of this is cultural socialization. Rollins and Hunter identify cultural socialization as the passing on of the traditions and values of parents' background(s). For example, by passing down personal knowledge, historical lessons, and recounts of their lived experiences, parents can promote the importance of group pride to their children. This type of socialization is considered to be "easier and occurs more naturally for these parents" compared to difficult discussions about race and discrimination (Rollins and Hunter, 2013, p. 142). The authors state, "mothers who engage in cultural socialization educate their children about current events and the history, heritage, and legacy of their people and encourage youth to take part in cultural activities. These practices aid in biracial child's development of a positive racial identity" (Rollins and Hunter, 2013, p. 142).

Le Gall and Meintel are two researchers who studied the various types of cultural socialization practices used by interracial couples in Quebec, Canada. They were concerned with the types of practices that these parents use to transmit their heritages and cultures to their children. Eighty interracial couples between the ages of 25 to 40 with at least one child were interviewed. These interviews focused on how these parents exposed their children to aspects of their heritage including language acquisition, religion, cooking, music and teachings related to values and identity. Many of these parents revealed that they "strove to offer their children the widest range of "cultural resources" they could, with the perspective that "mixedess is beneficial for the child because it facilitates access to several cultures" (Le Gall \& Meintel, 2015, p. 118). The parents' strategies, which are discussed below, were aimed at providing their children access to all aspects of their mixed heritages, rather than orienting them to choose one aspect of their identity over the other. This parenting approach reflects a mixed collective style. Le Gall and Meintel note "this attitude differs from that of the majority of mixed couples interviewed in other national context, where the transmission of all the ethnic identity referents of the child's background is much less common" (2015, p. 124). This statement suggests that there are differences between the parenting studies of interracial couples in Quebec, Canada than in other national contexts. The researchers 
believe that because Quebec is a province that heavily promotes multilingualism and multiculturalism, interracial parents are much more likely to encourage their children to embrace their mixed identity (Le Gall \& Meintel, 2015).

The parents in this study also sought to transmit three important cultural aspects of their identities to their children; language, contact with extended family, and visitation to the parent's home country. Parents viewed language as a salient part of social identity and sign of belonging (Le Gall \& Meintel, 2015, p. 123). Many of the Quebecois parents in this study encouraged their child to learn the first language of their spouse. This is because they viewed multilingualism and diversity as positive elements of their child's mixed background, one that could offer them a sense of belonging. Language is also viewed as a means of communication to the extended family (Le Gall \& Meintel, 2015, p. 123). Many of the couples believed that their child's ability to communicate with extended family will have an important influence on "the cultural habitat they develop during their life" (Le Gall \& Meintel, 2015, p. 125). Aspects of this cultural habitat can be provided through contact with grandparents, other family members, community celebrations, parties, and language courses. These are all considered positive components of identity development. Lastly, a number of the couples in this study relied on visits to their significant others country of origin to facilitate their child's understanding and identification with their mixed heritage. These trips allow children to have a greater understanding of their parents' backgrounds. To conclude, the parents in this study viewed their child's "mixedness" as an extremely positive and beneficial component of their identity, one that can be facilitated through cultural socialization.

\section{Conclusion}

As mixed union relationships continue to increase within Canada, family structures will likely become more diverse in the decades to come. Interracial couples engage in a number of different parenting styles where they must negotiate on how to talk to their children about race, and what it means to come from two different cultures. The implications of these parenting practices should be closely examined if we want to understand how these children come to terms with who they are, while living in a country that claims to be "multicultural" in nature. Mental health professionals, school boards, child care practitioners and social workers will need to consider how being biracial can influence identity development.

The findings of this paper suggest that when conflict arises between interracial couples on how to appropriately talk to their child about race, a child will struggle to understand who they are. As a result, that child may lack self confidence and the necessary skills needed to tackle future challenges where they might encounter racial discrimination. There seems to be a limited number of studies related to interracial parenting in Canada. More data needs to be collected to give us insight on what it means to be parent of a biracial child in a multicultural society. To conclude, there are many socialization practices that interracial parents can engage in to promote their child's understanding of who they are. Parents need to be able to have frequent and open conversations about race with their children. Cultural practices within the home can help biracial children recognize who they are and feel a sense of belonging with both heritages. 


\section{References}

Berray, M. (2019). A Critical Literary Review of the Melting Pot and Salad Bowl Assimilation and Integration Theories. Journal of Ethnic and Cultural Studies, 6(1), 142-151. doi: $10.29333 /$ ejecs/217.

Brooks, C. (2007, November). Parental communication and its influence on Biracial identity. Paper presented at the annual meeting of the NCA 93rd Annual Convention, Chicago, IL. Retrieved from http://allacademic.com

Brown, C. S., Alabi, B. O., Huynh, V. W., \& Masten, C. L. (2011). Ethnicity and gender in late childhood and early adolescence: group identity and awareness of bias. Developmental Psychology, 47(2), 463-471. doi: 10.1037/a0021819.

Crawford, S. E., \& Alaggia, R. (2008). The best of both worlds? Family influences on mixed race youth identity development. Qualitative Social Work, 7(1), 81-98. doi: 10.1177/1473325007086417.

Edwards, R., Caballero, C., \& Puthussery, S. (2010). Parenting children from "mixed" racial, ethnic and faith backgrounds: typifications of difference and belonging. Ethnic \& Racial Studies, 33(6), 949-967. doi: 10.1080/01419870903318185

Erikson, E. (1968). Identity, youth, and crisis. New York: Norton. Retrieved from https://academia.edu

Hamplova, D., \& Le Bourdais, C. (2010). Visible minorities and "White'-'non-White" conjugal unions in Canadian large cities. Ethnic and Racial Studies, 33(9), 1537-1560.

doi: 0.1080/01419871003743405

Herman, M. (2004). Forced to choose: some determinants of racial identification in multiracial adolescents. Child Development, 75(3), 730-738. doi: 10.111/j.1467-8624.2004.00703.x.

Ingram, P \& Chaudhary, A. (2014). Self-identity of biracial children: what role do parents play? Journal of Human Sciences and Extension, (2), 1. Retrieved from https://ingentaconnect.com

Jacobs, J. (1992). Identity development in biracial children. In M. Root (Ed.), Racially mixed people in America(190-206). Newbury Park, CA: Sage. Retrieved from https://psycnet.apa.org.

Jones, V. A. (2015). The black-white dichotomy of race: influence of a predominantly white environment on multiracial identity. Higher Education in Review, 12, 1-22. Retrieved from https://sites.psu.edu.

Kouritzin, S. G. (2016). Mothering across colour lines: decisions and dilemmas of white birth mothers of mixed-race children. Journal of Multilingual and Multicultural Development, 37(8), 735-747. doi: 10.1080/10434632.2015.1122604.

Lalonde, R. N. (2002). Testing the social identity-intergroup differentiation hypothesis: "We're not American eh!" British Journal of Social Psychology, 41(4), 611 doi: $0.1348 / 014466602321149902$.

Lalonde, R. N., Giguère, B., Fontaine, M., \& Smith, A. (2007). Social dominance orientation and ideological asymmetry in relation to interracial dating and transracial adoption in Canada. Journal of Cross-Cultural Psychology,38(5), 559-572. doi: $10.1177 / 0022022107305238$ 
Lamb, L. (1999). Parenting and child development in non-traditional families. Journal of Child and Psychology and Psychiatry, 43(1). doi: 10.2307/354032.

Le Gall, J., \& Meintel, D. (2015). Cultural and identity transmission in mixed couples in Quebec, Canada: normalizing plural identities as a path to social integration. The Annals of the American Academy of Political and Social Science, 662 (1), 112-128. doi: 10.1177/0002716215602705

Melina, L. (1990). Racial identity of children of mixed heritage still controversial. Adopted Child, 9(5), 1-3. Retrieved from http://academic.oup.com.

O'Donoghue, M. (2004). Racial and ethnic identity development in white mothers of biracial, black-white children. AFFILIA: Journal of Women and Social Work, 19(1), 68-84. Retrieved from: https://journals.sagepub.com

Poston, W. S. C. (1990). The biracial identity development model: a needed addition. Journal of Counseling and Development, 69, 152-155. Retrieved from https://onlinelibrary.wiley.com

Rockquemore, K., \& Laszloffy, T. A. (2005). Raising biracial children. AltaMira Press. Retrieved from https://books.google.ca

Rollins, A., \& Hunter, A. (2013). Racial socialization of biracial youth: maternal messages and approaches to address discrimination. Family Relations, 62(1), 140-153. doi: 10.1111/j.1741-3729.2012.00748.x

Root, M. P. P. (2003). Racial identity development and persons of mixed-race heritage. The multiracial child resource book: Living complex identities, 34-41. Seattle, WA: Mavin Foundation. Retrieved from https://books.google.ca

Root, M. P. (2005). Resolving "other" status: Identity development of biracial individuals. ASHE reader on college student development theory. Retrieved from https://tandfonline.com

Statistics Canada. (2008). Canada's ethnocultural mosaic, 2006 census. Catalogue No. 97-562X. Retrieved from https://dsp-psd.pwgsc.gc.ca/collections Statistics Canada. (2011).

Mixed unions in Canada. National Household Survey 2011. $\quad$ Catalogue $\quad$ no. 99-010X2011003. Retrieved from http://12.statcan.gc.ca 